\title{
Ergonomics of a Chinese Folk Bamboo Lounge Chair
}

\begin{abstract}
Yifei Cheng, ${ }^{\mathrm{a}}$ Onder Tor, ${ }^{\mathrm{b}}$ Lingling $\mathrm{Hu},{ }^{\mathrm{a}}$ Wei Zheng, ${ }^{\mathrm{c}}$ and Youming $\mathrm{Yu}{ }^{\mathrm{a}, *}$
Bamboo is an environmentally friendly sustainable resource and is commonly used in furniture production in China. Limited research has been conducted in the field of ergonomics of bamboo furniture, which can greatly affect the seating experience. This study provides a qualitative and quantitative analysis of the main effects of seat surface curve, bending deflection of bamboo strips of seat, functions, and usability in a bamboo lounge chair provided in Zhejiang Province. The shape of the seat surface curve of the bamboo lounge chair included the seat-back angle of $134^{\circ}$, and the slope of the bamboo lounge chair seat was $16^{\circ}$. The deflection of bamboo strips of seat under vertical loading force of $336 \mathrm{~N}$ was $30.7 \mathrm{~mm}$. In addition, the angles, deflection characteristic, and functions of the bamboo lounge chair were all human-centered design and suitable for human comfort, which can reduce maximum pressure and maintain normal lumbar spine curve in adult.
\end{abstract}

Keywords: Bamboo lounge chair; Furniture; China; Ergonomics; Human-centered design;

Contact information: a: School of Engineering, Zhejiang Agriculture and Forest University, Hangzhou, Zhejiang Province 311300 P. R. China; b: Department of Forest Industry Engineering, Faculty of

Forestry, Kastamonu University, Turkey c: Department of Art \& Design, Jiyang College of Zhejiang A\&F

University, Zhuji, Zhejiang Province 311800 P. R. China;

* Corresponding author: yuyouming@zafu.edu.cn

\section{INTRODUCTION}

As the global area of forest resources decreases, there is a contradiction between the sustainable management of forest resources and the increase in demand for wood. One solution is bamboo, which is widely used for furniture design. Bamboo is a renewable and sustainable material for furniture design, and it has many advantages, such as rapid growth, high tensile strength, low weight, fire resistance, flexibility, cost effectiveness, and ease of use (Scurlock et al. 2000; Zhang 2014; Chen et al. 2019).

Bamboo can be processed into a large curvature arc, which makes the furniture shape more varied to adapt to various conditions under hot pressing (Wang 2015). In addition to its unique structural properties, bamboo is also skin-friendly and comfortable with natural appearance. It has the effect of feeling warm in winter and cool in summer. Therefore, fast-growing bamboo is a natural alternative to meet the high demand from the household market (Qiu et al. 2019).

Approximately $70 \%$ of the bamboo forest in Asia is in China and India. There are more than 40 genera and 500 species, with 6.01 million $\mathrm{hm}^{2}$ of bamboo forest, which accounts for about 1/3 of the total bamboo forest area in the world (Qiu et al. 2019). Bamboo furniture has a long history in China (Fang and Chen 2002; Fang and Wang 2015). It is rooted in the simplicity of daily life and maintained harmony with the environment (Fig. 1), but the design and manufacture of bamboo furniture is based on the experience of craftsmen, which is not related to the principle of ergonomics. 
Most studies of bamboo furniture focus on technology innovation (Xia et al. 2017; Sofiana et al. 2017; Wang et al. 2017, 2018a), marketability (Majumdar et al. 2017), or aesthetics and culture (Sun and Li 2014; Fang and Wang 2015; Lei and Wang 2015). However, there has been limited research in the field of ergonomics for bamboo furniture. Cheng et al. (2017) evaluated new bamboo furniture through examining the relationship between design and value in Taiwan and reported that if the bamboo furniture's "human factors" were not satisfactory, then the "aesthetic sensitivity", "usability", and "marketability" were not satisfactory to consumers either.

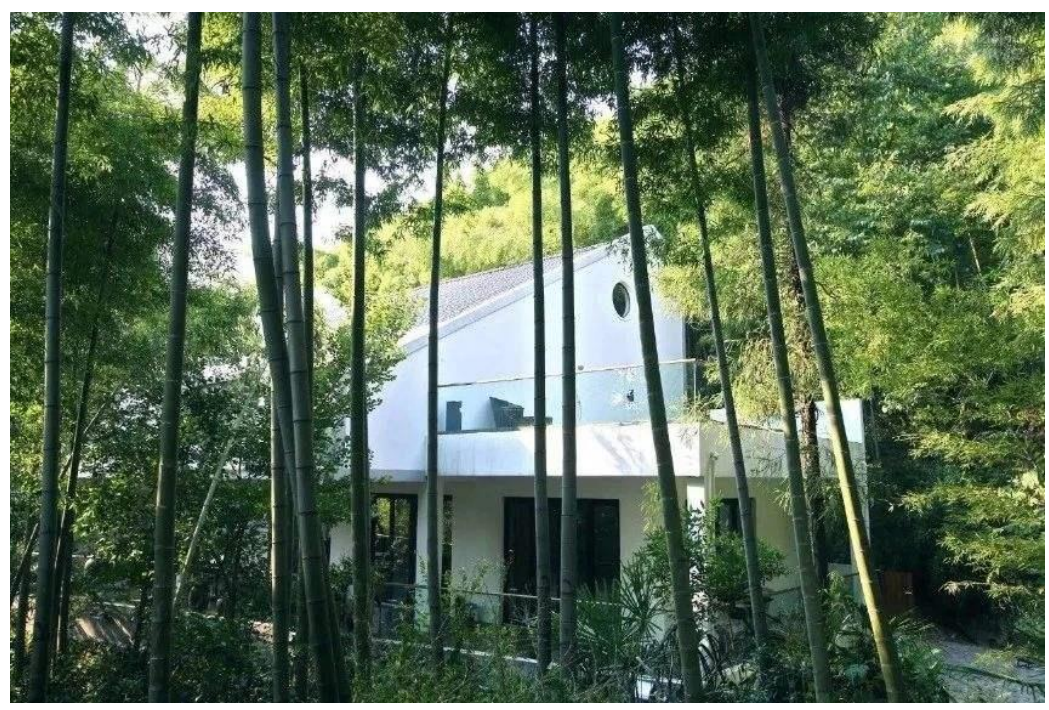

Fig. 1. Bamboo in rural China

Detachable structures of traditional bamboo furniture have been analyzed and explored to improve the multi-functional use (Li 2014). In Sichuan Province, the users' experience and modern use scenarios are the critical elements of bamboo furniture design after the product process and structure of bamboo furniture (Fang and Wang 2015; Wang et al. 2017, 2018b). Finite element analysis has been used to compare the mechanical properties of wood and bamboo furniture, and bamboo's processing performance has been found to be similar to that of hardwood, indicating that bamboo is an ideal material for furniture making (Fu and Fang 2016; Zhu 2013). The mechanical properties in bamboo furniture have been analyzed to highlight the importance of considering material when designing the classification structure and multi-scale mechanical properties of bamboo furniture cases (Wang et al. 2018a; Wu et al. 2018). The durability of the treated strip has been evaluated to calculate the deflection of magazine shelf made by bamboo (Adewole and Bello 2013).

This study analyzed the qualitative and quantitative data of the main effects of seat surface curve, peak deflection seat, functions, and usability for the Chinese folk bamboo lounge chair. The specific objectives were as follows: 1) to investigate the dimensions and surface shape of the bamboo lounge chair; 2) to evaluate the deflection of the bamboo lounge chair when occupied in a recumbent position; and 3) to analyze the dimensions of footstool, armrest, and backrest from the perspective of functions. This study will help bamboo furniture manufacturers to understand the people-oriented design thougths in history of bamboo chair in China and evaluate bamboo furniture based on modern ergonomics. 


\section{EXPERIMENTAL}

\section{Materials}

The main focus of the experiments was to evaluate the ergonomics of a lounge chair made of bamboo material. Bamboo furniture has a variety of types such as bed, cabinet, seat, table, among which the seat is the most widely used one, which can be divided into stool, seat, and reclining chair. Among the three, the lounge chair has the most comprehensive parts for ergonomics, so this paper used a bamboo lounge chair as the research and analysis object. The popular bamboo lounge chair provided in Zhejiang province was selected and used for different purposes such as reading, caring, and resting activities as shown in Fig. 2. For targeted analysis, the bamboo lounge chair was divided into 4 parts including seat surface curve, seat, footstool, and armrest.

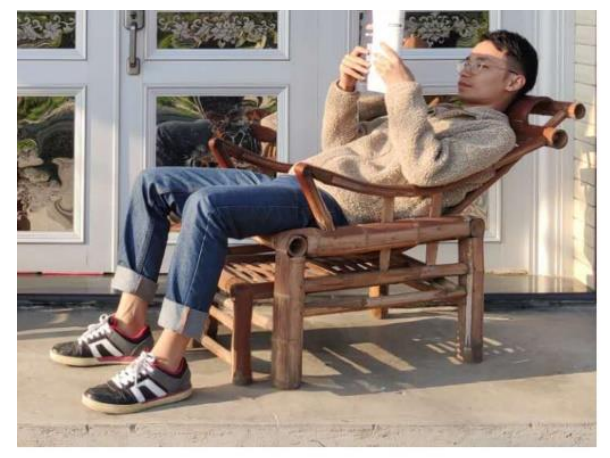

a. Reading without footstool

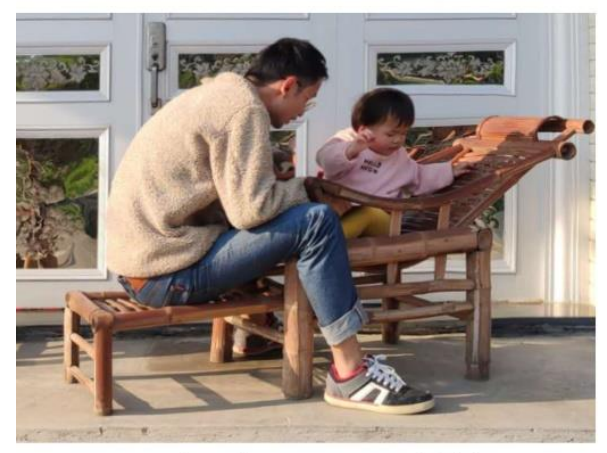

c. Caring for a young child

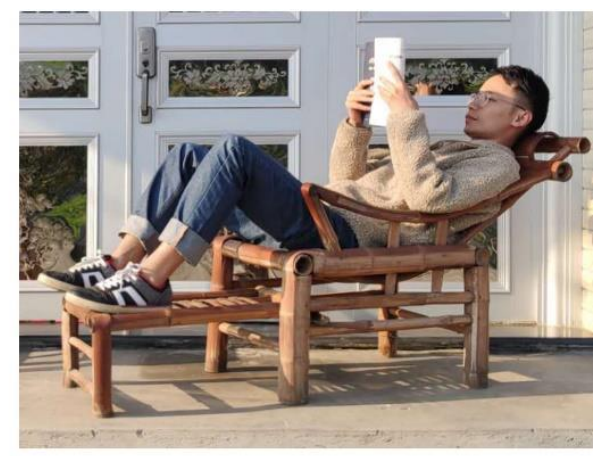

b. Reading with footstool

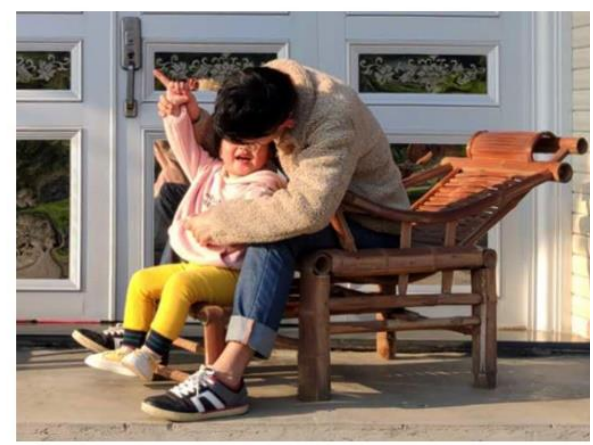

d. Caring for a young child

Fig. 2. The purposes of using the bamboo lounge chair

\section{Methods}

Basic Dimension of the Bamboo Lounge Chair

The basic dimensions of the bamboo lounge chair are summarized in Fig. 3, which is based on the Human Dimensions of Chinese Adults (GB/T10000-88 1988) (Table 1). The dimensions of each part of the bamboo lounge chair were compared to the dimensions of normal chair in GB/T 10000-88 (1988) from the table of horizontal dimensions of human body. Most of the dimensions of bamboo lounge chair were in line with the standard, but not in height and angle. The seat-back angle of the bamboo lounge chair was $134^{\circ}$, and the corresponding angle of the normal chair in GB/T 10000-88 (1988) is no more than $130^{\circ}$. The height of the bamboo lounge chair was $40 \mathrm{~mm}$ lower than the corresponding one in the standard. 


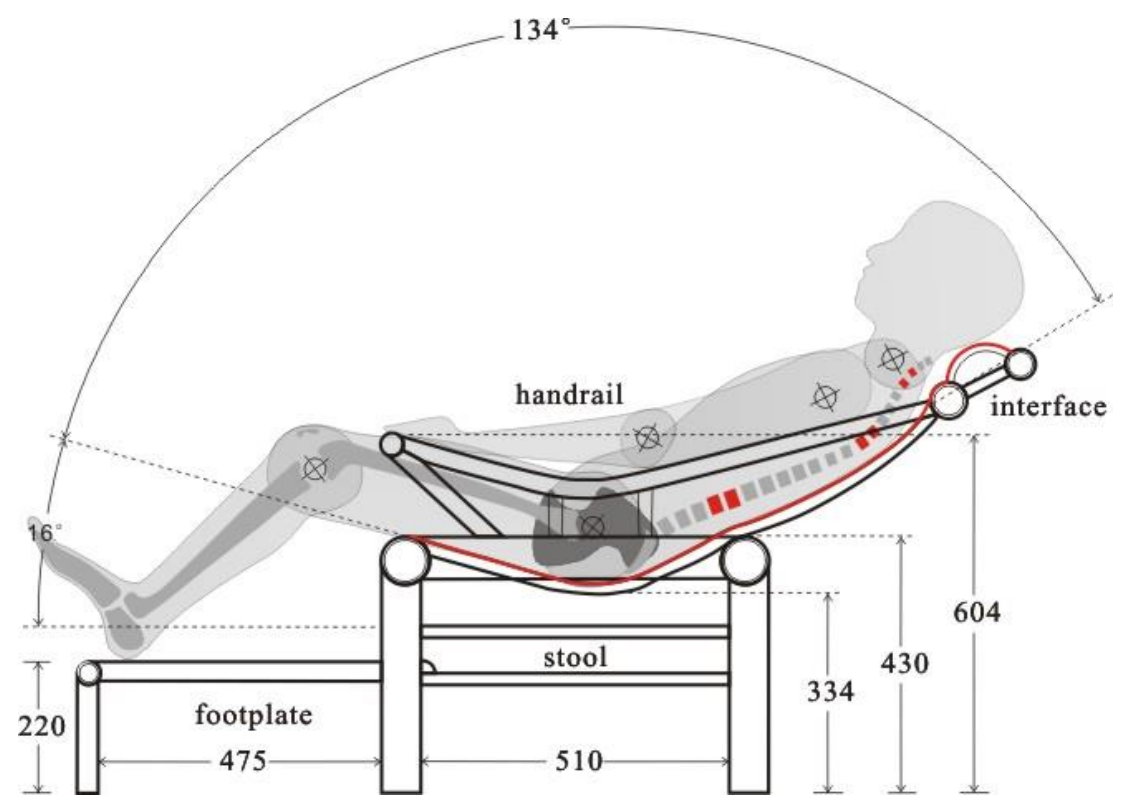

Fig. 3. Dimensions of the bamboo lounge chair ( $\mathrm{mm})$

Table 1. Functional Dimensions of Each Part of Bamboo Lounge Chair

\begin{tabular}{|l|c|c|c|}
\hline \multicolumn{1}{|c|}{ Parts of the chair } & $\begin{array}{c}\text { Dimension of the } \\
\text { chair }\end{array}$ & $\begin{array}{c}\text { Standard dimension } \\
\text { of chairs }^{\text {a }}\end{array}$ & Difference \\
\hline Slop of chair seat & $16^{\circ}$ & $<12^{\circ}$ & $4^{\circ}$ \\
\hline Seat-back angle & $134^{\circ}$ & $<130^{\circ}$ & $4^{\circ}$ \\
\hline Seat height from floor $(\mathrm{mm})$ & $334 \sim 430$ & $389 \sim 399$ & -60 \\
\hline Seat width $(\mathrm{mm})$ & 420 & $318 \sim 347$ & 80 \\
\hline Seat depth $(\mathrm{mm})$ & 510 & & \\
\hline Height of the footstool $(\mathrm{mm})$ & 220 & & \\
\hline $\begin{array}{l}\text { Length of the footstool } \\
\text { (mm) }\end{array}$ & 475 & & -63 \\
\hline Width of the footstool $(\mathrm{mm})$ & 360 & $237 \sim 277$ & \\
\hline $\begin{array}{l}\text { Armrest height from seat of } \\
\text { chair (mm) }\end{array}$ & 174 & \\
\hline${ }^{a}$ Dimensions in GB10000-1988.
\end{tabular}

\section{Methods for Calculating the Bending Deflection of the Seat}

The seat surface curve was divided into four parts, leg area with $16^{\circ}$, hip area contained the seat, trunk area with $30^{\circ}$, and head area next to the trunk area. The final force exerted on the hip cushion under the resultant force of leg, trunk, and head parts was calculated.

Then, the bending deflection of bamboo sheets of seat were calculated with the final force exerted on the hip cushion according to the two-points-deflection equation (Liu et al. 2011). The calculation result was compared with the deflection of cushions constructed with other materials along with the MOR (Modulus of rupture) and MOE (Modulus of elasticity) of bamboo sheet. 


\section{RESULTS AND DISCUSSION}

\section{The Shape of Seat Surface Curve}

According to the principles of ergonomics, posture holds the body upright against gravity while standing, sitting, or lying down. The proper posture should have good muscle flexibility, strong postural muscles, normal position in the joints, and a balance of spine muscles to feel comfortable while in a chair. The angle between the seat surface and curvature of the spine is used as a reference for the analysis of the curve shape.

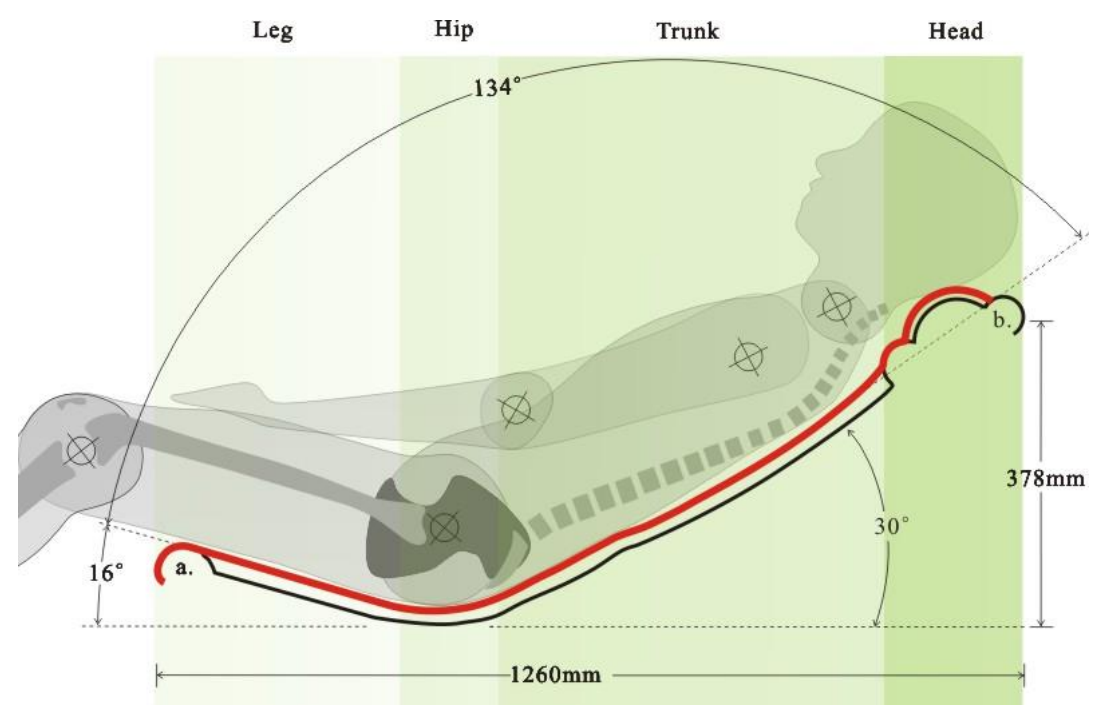

Fig. 4. Different parts of the chair

The whole curve of the seat surface is constructed with heat-treated long bamboo pieces to support the parts of the human body at different degrees. The curve shape of the seat surface was divided into four parts (Fig. 4), which are described below.

\section{Leg area}

The angle of the seat inclination is $16^{\circ}$ from the vertical, which can prevent the body from sliding forward. It reduces the physiological and psychological fatigue caused by sliding when sitting with or without a footstool (Fig. 2a, b.). In addition, the seat inclination supports the feet and legs, reducing the nerve compression in legs caused by the low chair height when sitting properly in the bamboo lounge chair without the footstool (Fig. 2d).

\section{Hip area}

The large arc angle between the seat and the back in hip area is $134^{\circ}$. The design of seat-back angle is based on the health of lumbar spine and the normal curve of the lumbar spine in adult is determined by maintenance of the trunk-thigh and knee angles at approximately $135^{\circ}$ (Keegan 1953; Jalkanen 2004; Computer chair 2017). With the increase of leg angle, the load of lumbar vertebrae and thoracic vertebrae decreases, and the shape of spine is similar to the S-shape formed naturally when standing. It helps most of the weight to be borne by the backrest. The blood vessels between the abdomen and thigh are not squeezed, and the blood flow is smooth. With the $16^{\circ}$ seat angle and $134^{\circ}$ seat-back angle, body pressure is more concentrated in the ischial tubercle of the hip area 
than in the legs or waist. The ischial tubercle is relatively thick with an area of $25 \mathrm{~cm}^{2}$ under the pelvis, and there are fewer blood vessels and nerves distributed here. It can bear more pressure than the surrounding muscles to reduce nerve compression in other areas, avoiding muscle fatigue, cramping, and leg pain (Bush et al. 1999).

\section{Trunk area}

The trunk is the largest area of the upper body and the most load-bearing. This area has an angle of almost $30^{\circ}$ between the seating surface and horizontal inner surface. With regard to back elevation, the maximum reduction of pressure on the hip and whole body occurs when the back is raised by $30^{\circ}$; at this angle, there is uniform pressure distribution on the hip (Defloor 2000; Harada et al. 2002; Lyder 2002; Stinson et al. 2003; Marco et al. 2012).

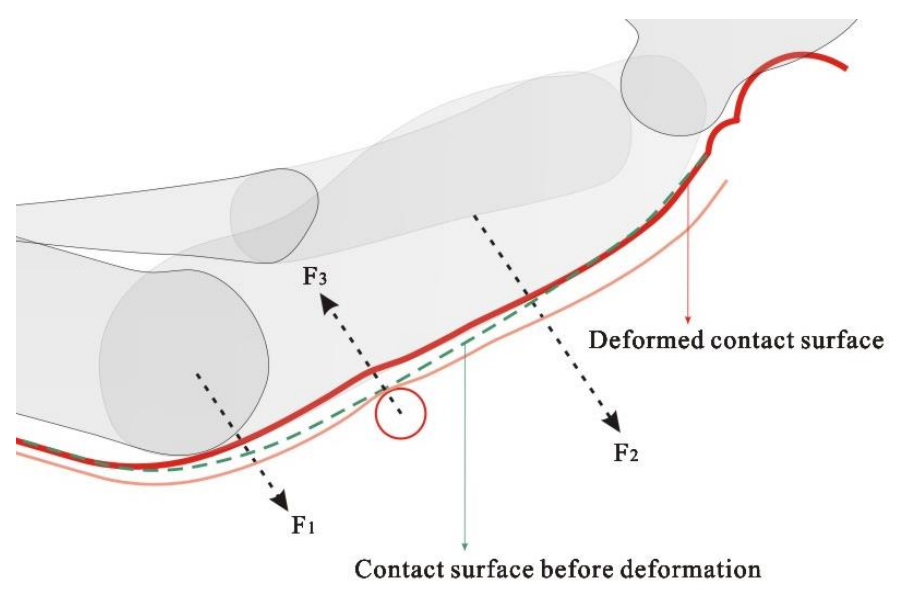

Fig. 5. Seat contact surface deformation. Red circle: bamboo support connection under the contact surface

The main structure supporting upper part of the human body is the spine, which is composed of 33 cylindrical vertebrae, including 5 lumbar vertebrae when a person is lying. Therefore, the comfort design of trunk area is closely related to the spine. The trunk area is supported by whole elastic long bamboo strips. The human body exerts the forces of $F_{1}$ and $F_{2}$ on the trunk area, and the support structure under the contact surface produces $F_{3}$ support force to the contact surface (Fig. 5). After long use, a lumbar support that conforms to the curve of the user's waist can be produced at the 4-5 lumbar vertebrae. The naturally produced lumbar support can relieve the fatigue of the waist when lying for a long time and reduce the deformation of the lumbar spine.

\section{Head area}

The elastic headrest is made of thin bamboo strips and half round bamboo arc structure. It provides support in line with the shape of the cervical vertebra, keeping the spine in a normal posture and avoiding muscle fatigue.

\section{Bending Deflection of Bamboo Sheets of Seat}

To analyze the stiffness of the bamboo lounge chair, the ultimate load applied on each part of the bamboo lounge chair and bending deflection of the seat were calculated and compared with the deflection of cushions constructed with other materials along with the modulus of rupture (MOR) and modulus of elasticity (MOE) of bamboo sheet. A-75kg- 
male participant was selected based on 95 th percentile of male aged 18- to 60-years-old (GB/T10000-88, 1988) to present $95 \%$ of users.

The contact surface of the bamboo lounge chair is made by arranging several pieces of bamboo with $420 \mathrm{~mm}$ in length, $20 \mathrm{~mm}$ in width, and $5 \mathrm{~mm}$ in height side by side. The hip contact surface of the bamboo seat can approximately be considered as a cube with 420 $\mathrm{mm}$ in length, $80 \mathrm{~mm}$ in width and $5 \mathrm{~mm}$ in height to analyze the stiffness (Fig. 6). Table 2 shows the dimensions and ultimate load of each area of the bamboo lounge chair.
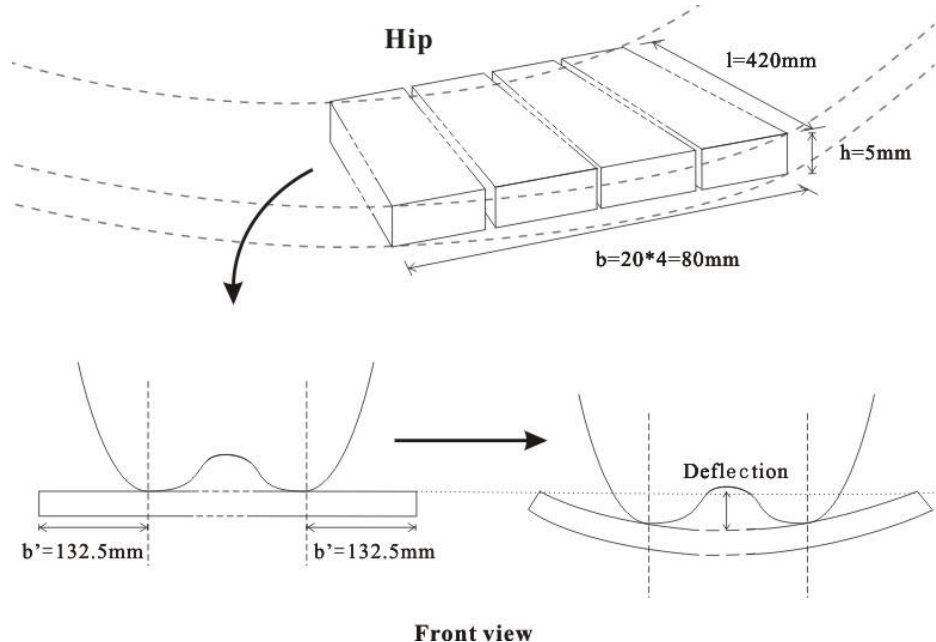

Fig. 6. Detailed dimensions and deformation shape of bamboo cushion

The MOR of bamboo sheet is $221.6 \mathrm{MPa}$ (Li et al. 2013). The ultimate load can be calculated according to the following equations,

$$
\begin{aligned}
& S * \text { MOR }>P \\
& P=F / S
\end{aligned}
$$

where $S$ is the contact area, MOR is the static bending strength of bamboo sheet, $P$ is the pressure of contact surface, and $F$ is the loading force.

Table 2. Dimensions and Ultimate Load of Each Part of Body of the Chair

\begin{tabular}{|c|c|c|c|c|}
\hline Parts of body & Leg & Hip & Trunk & Head \\
\hline Horizontal length $(\mathrm{mm})$ & 300 & 80 & 730 & 50 \\
\hline Angle & $16^{\circ}$ & $0^{\circ}$ & $30^{\circ}$ & $0^{\circ}$ \\
\hline Contact length $(\mathrm{mm})$ & 300 & 80 & 421 & 50 \\
\hline Width $(\mathrm{mm})$ & \multicolumn{4}{|c|}{0.42} \\
\hline Square $\left(\mathrm{mm}^{2}\right)$ & 126000 & 33600 & 306600 & 21000 \\
\hline$F_{\max }$ & $3.8 \times 106$ & $2.5 \times 105$ & $6.9 \times 106$ & $9.8 \times 104$ \\
\hline
\end{tabular}

The $95^{\text {th }}$ percentile male weight of $75 \mathrm{~kg}$ in China was allocated according to the ratio of 0.222:0.342:0.355:0.081 (Moon et al. 2005). Gravity in Table 3 is the body weight of each part, $F_{\mathrm{a}}$ is the force exerted by gravity on the contact surface vertically, and $F_{\mathrm{b}}$ is the final force exerted on the hip cushion under the resultant force of $F_{1}, G_{2}$, and $F_{3}$ (Fig. 7). 
Table 3. Approximate Weights of Each Part of Body

\begin{tabular}{|c|c|c|c|c|}
\hline Parts of body & Leg & Hip & Trunk & Head \\
\hline Weight & $0.222 \mathrm{w}$ & $0.342 \mathrm{w}$ & $0.355 \mathrm{w}$ & $0.081 \mathrm{w}$ \\
\hline Gravity $(\mathrm{N})$ & 166.5 & 256.5 & 266.25 & 60.75 \\
\hline$F_{\mathrm{a}}(\mathrm{N})$ & 160.056 & 256.5 & 230.573 & 60.75 \\
\hline$F_{\mathrm{b}}(\mathrm{N})$ & & 335.89 & & \\
\hline
\end{tabular}

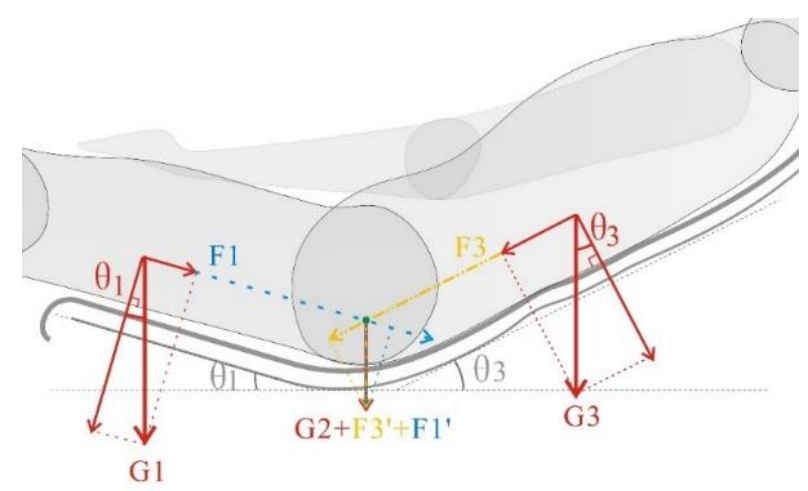

Fig. 7. Analysis of hip force $\left(\mathrm{F}_{\mathrm{b}}=\mathrm{G}_{2}+\mathrm{F}_{3}{ }^{\prime}+\mathrm{F}_{1}{ }^{\prime} ; \mathrm{F}_{\mathrm{a} 1}=\mathrm{G}_{1} ; \mathrm{F}_{\mathrm{a} 2}=\mathrm{G}_{2} ; \mathrm{F}_{\mathrm{a} 3}=\mathrm{G}_{3}\right)$

The following equation was used to calculate the maximum bending deflection of the bamboo seat under two points forces, with the MOE of 16.63 GP (Liu et al. 2011; Li et al. 2013) as,

$$
\begin{aligned}
& W_{\mathrm{c}}=\frac{F b\left(3 l^{3}-4 b^{2}\right)}{48 E I} * 2 \\
& I=\frac{b h^{3}}{12} \\
& W_{\mathrm{c}}=\frac{F b\left(3 l^{2}-4 b^{2}\right)}{2 E b^{\prime} h^{3}}
\end{aligned}
$$

where $W_{\mathrm{c}}$ is the bending deflection of bamboo sheet $(\mathrm{mm}), F$ is the final force loading vertically $\left(F_{\mathrm{b}}=336 \mathrm{~N}\right), l$ is the length of bamboo sheet $(420 \mathrm{~mm}), E$ is the MOE $(16.6 \mathrm{GP})$, $I$ is the moment of inertia, $b$ is the distance between ischium and edge of seat (132 $\mathrm{mm}), b$, is the rectangle width $(20 * 4=80 \mathrm{~mm})$, and $h$ is the rectangle height $(5 \mathrm{~mm})$.

Deflections of cushions constructed with different materials under the vertical loading force $336 \mathrm{~N}$ were compared. The bending deflection of the bamboo lounge chair under $336 \mathrm{~N}$ was $30.7 \mathrm{~mm}$. Ebe and Griffin (2001) investigated the relationship between the static physical characteristics of a cushion and seat comfort, concluding that the material of $25 \%$ ILD hardness of high durability was the most comfortable. The deformation under the vertical loading force $336 \mathrm{~N}$ was $31 \mathrm{~mm}$. The deflection characteristics on flat and contoured foams were analyzed; sitting on contoured foam resulted in a lower pressure distribution than sitting on flat foam. The deformation of a HR55 flat foam cushion with $75 \mathrm{~mm}$ thickness was $38 \mathrm{~mm}$, which was the most comfortable object among flat foams in this study. The deformation of contoured foam was inferred which was less than $38 \mathrm{~mm}$ (Sprigle et al. 1990). Vlaović et al. (2010) studied mechanical comfort that the chair can offer to the user and concluded that MA2 had the highest comfort index/support factor for chair models. The deformation of MA2 under the vertical loading force $336 \mathrm{~N}$ is $29.5 \mathrm{~mm}$ (Vlaović et al. 2010). This shows that the bamboo seat has the same deflection as other materials in normal use. Thus, the bamboo lounge chair was relatively comfortable. 


\section{Multi-functions Fit the Needs of People in Rural China}

The bamboo lounge chair came from rural areas in China. The user groups were farmers and elderly, who were the main population in rural China. The multi-functions of the bamboo lounge chair were designed based on those people's living habits and social activities, which made bamboo furniture unique. Because the functions of the bamboo lounge chair were different from normal chairs, its dimensions were different. The difference in dimensions of bamboo lounge chair and normal chair in the GB10000 (1988) (Table 1), showed that the sitting height and armrest height of the bamboo lounge chair was lower than the corresponding ones in the normal chair in the GB10000 (1988), but there was no information about the footstool. Therefore, in this section, the functions of working, resting, and social activities of people in China were analyzed based on the parts of the bamboo lounge chair. In addition, the manufacturing process of footstool, armrest, and seat surface of the bamboo lounge chair was analyzed.

\section{Footstool}

Bamboo lounge chairs are widely used in rural areas in China where individuals have a wide range of characteristics such as age and height. In order to meet the comfort needs of these individuals, chair designers set the footstool to stretch freely. The footstool can be disassembled and reused, which is convenient for its replacement (Fig. 8).

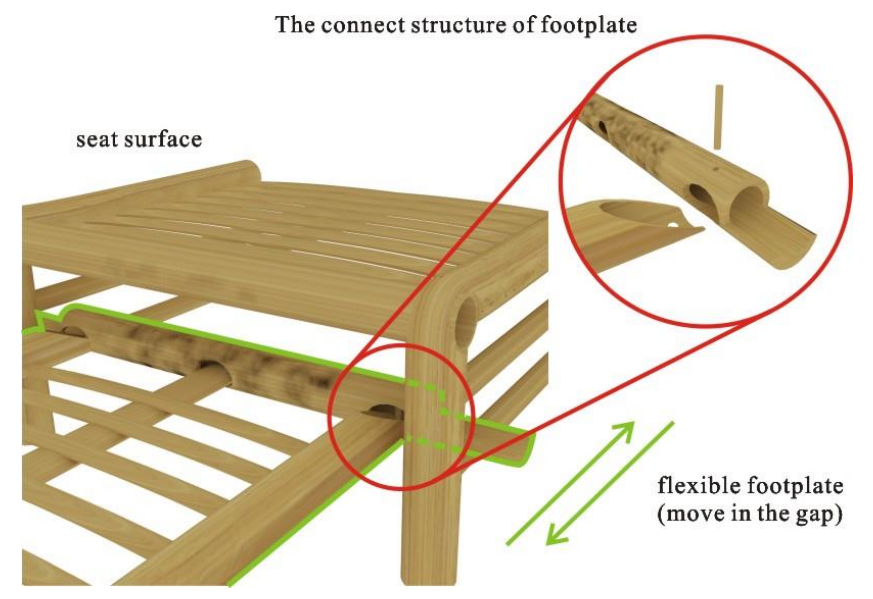

Fig. 8. The connection structure of flexible footstool of the bamboo lounge chair

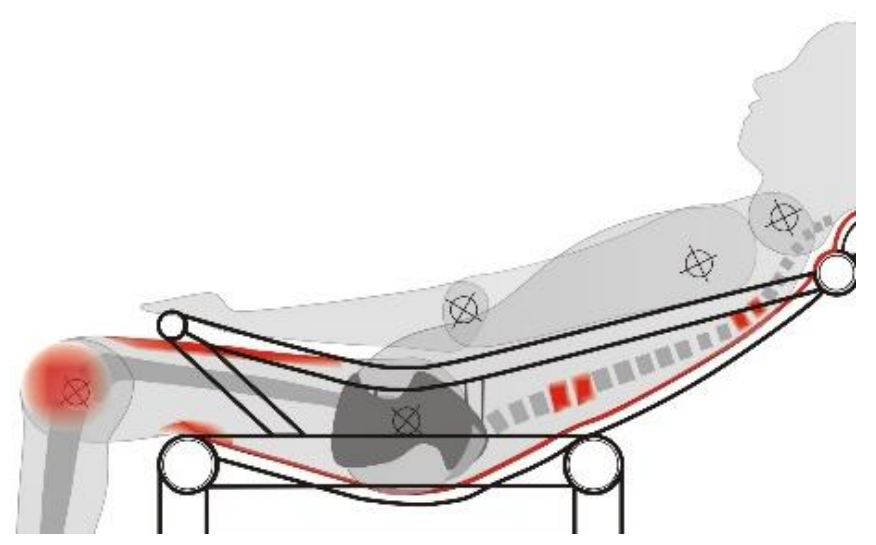

Fig. 9. Main stressed parts of the chair without footstool 
The footstool prevents the leg and knee of the human body from being sheared by the opposite side of the leg and upper body when lying down. This reduces the internal pressure of the knee and the squeezing of the upper and lower muscles of the thigh, so as to avoid obvious discomfort. The lowest height of the seat surface was $340 \mathrm{~mm}$ where the knee position was higher than the hip position. Multiple discomfort occurred when the chair is used for normal sitting for a long time (Fig. 9). Chaffin et al. (2006) indicated that a person needed to stretch his legs in any directions forward when the user lowers the center of gravity in a lying position in a chair in which the knee socket and bottom of thigh of the person were not pressed in order to avoid leg numbness, aching excessive bending angle of the body, extrusion of the stomach and abdomen, and low back pain caused by excessive load of waist muscles (Chaffin et al. 2006). Therefore, the footstool can effectively increase the comfort of the person sitting in the chair.

Fig. 10. Child-care activities in the bamboo lounge chair

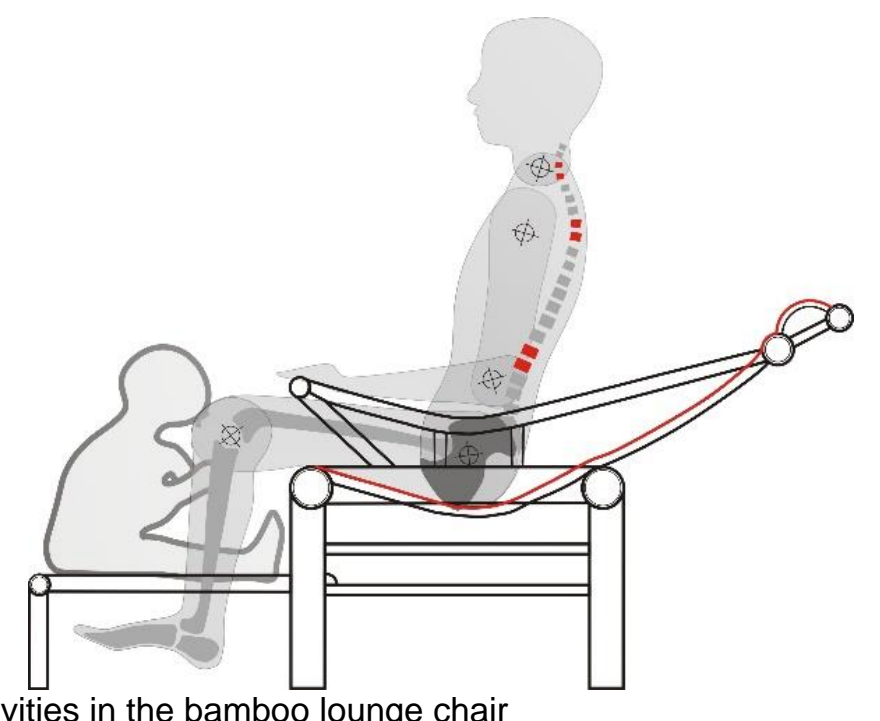

The second function of the footstool is to take care of a child in the chair (Figs. 2, 10). Children in rural China are often raised by grandparents, so many users of the bamboo lounge chair are the elderly and children. Based on the physical characteristics of the elderly, they always take care of their children closely and do many things for them such as feeding. Therefore, the footstool is a necessary part where a child is placed such that the parents easily can see the child.

The final function of the footstool is to use it as a desk. Some Chinese farmers used to sit on the low seat surface, putting labor supplies conveniently on the surrounding ground, and using this ground as the operation platform of daily activities.

\section{Armrest}

The shape of the handrail was aligned similar to the curve of the seat surface, forming a trend of "low elbow and high palm". It always keeps a relative height of $200 \mathrm{~mm}$ higher than the seat surface, which is in line with the conclusion that the handrail height of is about $40 \%$ of the human height (Nag et al. 2008). The armrest also provides support for the reasonable placement of the arms, which can reduce the burden on the shoulders, promote the venous blood flow of the upper limbs, and increase comfort. The round and upturned handrail provides a force application point for the user when raising up from the chair, especially for elderly because of the $140^{\circ}$ back angle of the recliner. 


\section{Backrest}

The most unique function of the backrest is that it is easy to clean. Farmers in China rely on manual work, and they carry dust on them after working. Therefore, the arrangement of bamboo slices in the backrest (Fig. 11) allowed them to rest without changing clothes. Dust and dirt can fall directly from the bamboo gap, and it is quite easy to clean the bamboo lounge chair using water, which is the most convenient way. Furthermore, the grid and stable form along with the natural structural properties of bamboo provide better moisture absorption and air permeability, which can improve the thermal comfort of the chair (Bartels 2003).

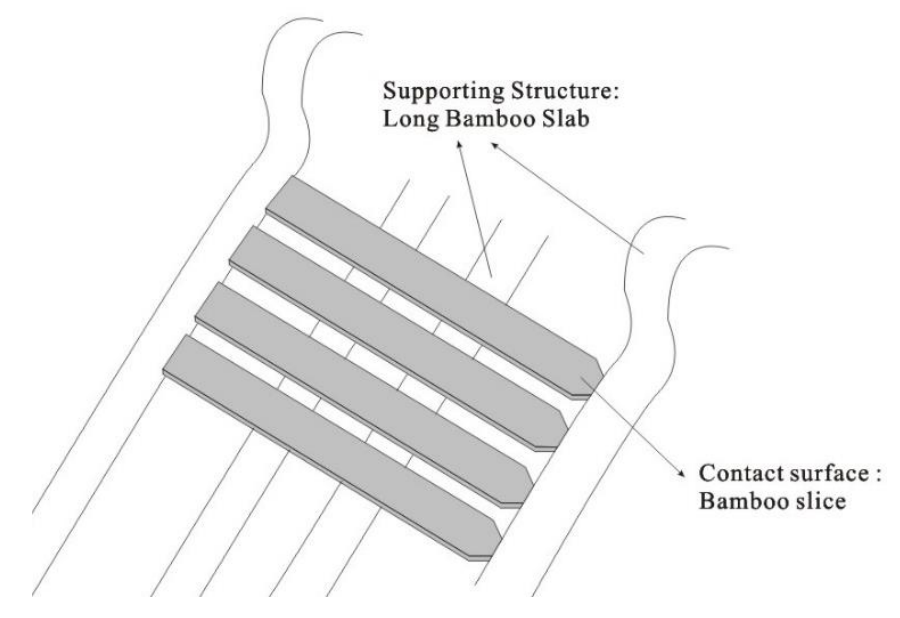

Fig. 11. Arrangement of bamboo strips on backrest

\section{Future Prospects}

The designers of the bamboo lounge chair paid more attention to the comfort and convenience of users, which coincided with today's people-oriented design concept and ergonomics. However, the traditional way of living habits suited to the traditional bamboo lounge chair have been changed a lot with the urbanization of China's population. Many design details can be improved by studying the modern way of living habits of the major consumer groups.

Bamboo furniture is more and more popular in China, but there must be a period of passing from manual to automated production. Therefore, the study in ergonomic analysis of traditional bamboo furniture is helpful for designers to extract essence from traditional bamboo furniture. The results of this paper might provide reference values for the design and application of modern bamboo furniture.

\section{CONCLUSIONS}

1. The angles of the seat surface curve in the studied traditional Chinese lounge charge all were consistent with scientific principles related to ergonomics.

2. The bending deflection of the bamboo seat was $30 \mathrm{~mm}( \pm 5 \mathrm{~mm})$, which was almost the same as the deflection of seats made of some other commonly employed materials 
for chairs, and the dimension difference between the bamboo lounge chair and normal chair were based on the unique living habits of people in rural China.

\section{ACKNOWLEDGMENTS}

This study was funded by Zhejiang Natural Science Foundation (China) [grant number LQ18C160002].

\section{REFERENCES CITED}

Adewole, N. A., and Bello, K. O. (2013). "Recycling of bamboo (Bambusa vulgaris Schrad) recovered from scaffold into material for furniture production," Innovative Systems Design and Engineering 4(9), 73-78.

Bartels, V. T. (2003). "Thermal comfort of aeroplane seats: Influence of different seat materials and the use of laboratory test methods," Applied Ergonomics 34(4), 393399. DOI: 10.1016/s0003-6870(03)00058-9

Bush, T. R., Gregg, S. J., and Hubbard, R. P. (1999). "Measuring and modeling support forces of people to assist in the development of the ASPECT Manikin weighting," SAE Transactions 108, 1776-1786. DOI: 10.2307/44733829

Chaffin, D. B., Andersson, G. B. J., and Martin, B. J. (2006). Occupational Biomechanics, $4^{\text {th }}$ Edition, John 2006 Wiley \& Sons, America.

Chen, Z., Zhang, H., He, Z., Zhang, L., and Yue, X. (2019). "Bamboo as an emerging resource for worldwide pulping and papermaking," BioResources 14(1), 3-5. DOI:10.15376/biores.14.1.3-5

Cheng, Y., Chen, C., and Cai, D. (2017). "An evaluation of new bamboo furniture: Through examining the relationship between design and value," Bulletin of Japanese Society for Science of Design 55, 93-102. DOI: 10.11247/jssdj.55.93

Computer chair (2017). "Computer disease is saved! Must learn three office postures!" (https://zhuanlan.zhihu.com/p/28495367), Accessed 13 August 2017.

Defloor, T. (2000). "The effect of position and mattress on interface pressure," Applied Nursing Research 13(1), 2-11. DOI: 10.1016/S0897-1897(00)80013-0

Ebe, K., and Griffin, M. J. (2001). "Factors affecting static seat cushion comfort," Ergonomics 44(10), 901-921. DOI: 10.1080/00140130110064685

Fang, H., and Chen, H. (2002). “ 'Chineseism' in modern furniture design -- Research on chair prototype," Art \& Design (03), 61-62. DOI: 10.16272/j.cnki.cn111392/j.2002.03.035

Fang, H., and Wang, X. (2015). "The introduction of bamboo from the East to the West: A comparative study of bamboo furniture cases between China and the West in Ming and Qing Dynasties," Journal of Nanjing Arts Institute(Fine Arts \& Design)(06), 7680. DOI: 10.3969/j.issn.1008-9675.2015.06.018

$\mathrm{Fu}$, Y., and Fang, H. (2016). "The application of the finite element method to verify the use of recombinant bamboo material in furniture," Journal of Bamboo Research 35(04), 48-54. DOI: 10.19560/j.cnki.issn1000-6567.2016.04.009

GB/T10000-88 (1988). "Human dimensions of Chinese adults," Standardization Administration of China, Beijing, China.

Harada, C., Shigematsu, T., and Hagisawa, S. (2002). "The effect of 10-degree leg 
elevation and 30-degree head elevation on body displacement and sacral interface pressures over a 2-hour period," Journal of WOCN: Wound, Ostomy and Continence Nursing 29(3), 143-148. DOI: 10.1067/mjw.2002.123645

Jalkanen, V. J. (2004). "Saddle seat for chair or stool," U.S. Patent No. US6709052 B2.

Keegan, J. J. (1953). "Alterations of the lumbar curve related to posture and seating," The Journal of Bone and Joint Surgery 35-A(3), 589. DOI: 10.1079/PNS19530066

Lei, D., and Wang, J. (2015). "The appearance design of bamboo-made furniture based on industrial design," Journal of Bamboo Research 34(04), 6-10. DOI: 10.3969/j.issn.1000-6567.2015.04.002

Li, J., Sun, Z., and Xu, M. (2013). "Evaluation and grading of bending properties moso bamboo strips near the bamboo green," Forestry Machinery \& Woodworking Equipment 41(08), 47-49+54. DOI: 10.3969/j.issn.2095-2953.2013.08.014

Li, N. (2014). "Primary researching the structure of original bamboo furniture," Art and Design (05), 120-121. DOI: 10.16824/j.cnki.issn10082832.2014.05.032

Liu, H., Lin, J., and Cao, M. (2011). Mechanics of Materials, $5^{\text {th }}$ Ed., Higher Education Press, Beijing, China.

Lyder, C. H. (2002). "Pressure ulcer prevention and management," AMA 289(2), 223-226. DOI: 10.1001/jama.289.2.223

Majumdar, P., Ji, S., and Banerjee, S. (2017). "Consumer preferences and value proposition disconnect-Assam rattan and bamboo furniture industry," in: International Conference on Research Into Design, Springer, Singapore, pp. 665-677.

Marco, R. A. W., Stuckey MD, R. M., and Holloway MHA, S. P. (2012). "Prolonged bed rest as adjuvant therapy after complex reconstructive spine surgery," Clinical Orthopaedics and Related Research 470(6), 1658-1667. DOI: 10.1007/s11999-0122318-3

Moon, I., Kang, S. J., Kim, G. S., and Mun, M. (2005). “A novel air-cell mattress based on approximate anthropometric model for preventing pressure ulcer," in: ICCA, KINTEX, Gyeonggi-Do, Korea.

Nag, P. K., Pal, S., Kotadiya, S. M., Nag, A., and Gosai, K. (2008). "Human-seat interface analysis of upper and lower body weight distribution," International Journal of Industrial Ergonomics 38(5-6), 539-545. DOI: 10.1016/j.ergon.2007.10.024

Qiu, H., Xu, J., He, Z., Long, L., and Yue, X. (2019). "Bamboo as an emerging source of raw material for householdand building products," BioResources 14(2), 2465-2467. DOI: 10.15376/biores. 14.2.2465-2467

Scurlock, J. M. O., Dayton, D. C., and Hames, B. (2000). "Bamboo: An overlooked biomass resource?” Biomass Bioenergy 19(4), 229-244. DOI: 10.1016/S09619534(00)0008-6

Sofiana, Y., Sylvia, C. O., and Purbasari, M. (2017). "Potential of bamboo as material for furniture in rural area in Indonesia," Advanced Science Letters 23(1), 263-266. DOI: 10.1166/asl.2017.7153

Sprigle, S., Chung, K. C., and Brubaker, C. E. (1990). "Reduction of sitting pressures with custom contoured cushions," Journal of Rehabilitation of Research and Development 27(2), 135-140. DOI: 10.1682/JRRD.1990.04.0135

Stinson, M. D., Porter-Armstrong, A., and Eakin, P. (2003). "Seat-interface pressure: A pilot study of the relationship to gender, body mass index, and seating position," Archives of Physical Medicine and Rehabilitation 84(3), 0-409. DOI: 10.1053/apmr.2003.50011

Sun, W., and Li, D. (2014). "The design aesthetics of traditional Chinese bamboo-rattan 
furniture," Journal of Bamboo Research 33(01), 52-58+62. DOI: 10.3969/j.issn.10006567.2014.01.010

Vlaović, Z., Grbac, I., Domljan, D., and Bublić, A. (2010). “Office work chairs Research of deformations and comfort index," Drvna Industrija 61(3) 159-168. DOI: 10.1007/s00226-009-0268-z

Wang, Y. (2015). The Applied Research of Bamboo Furniture Design in Chinese Northern Living Room, Master's Thesis, Taiyuan University of Technology, Taiyuan, China.

Wang, H., Lv, Y., Sun, X., Duo, H., Ma, K., and Zhang, C. (2018a). “A study on application of mechanical properties of moso bamboo to bamboo furniture," World Bamboo and Rattan 16(04), 15-17+66. DOI: 10.13640/j.cnki.wbr.2018.04.004

Wang, M., Fang, H., and Zhong, C. (2018b). "Research on the development of Yiyang Bamboo chairs and their contemporary applicability," Art \& Design 12, 109-111. DOI: 10.16272/j.cnki.cn11-1392/j.2018.12.023

Wang, M., Fang, H., and Zhong, C. (2017). "Research on the development directions of Xiaoyu bamboo crafts in Yiyang under the modern background - Taking the square stool as an example," Furniture \& Interior Design 11, 78-79. DOI: 10.16771/j.cn43$1247 /$ ts.2017.11.013

Wu, J., Fang, H., and Zhong, C. (2018). "Multi-scale mechanical properties of bamboo and their application in design," World Bamboo and Rattan 16(05), 15-19. DOI: 10.13640/j.cnki.wbr.2018.05.003

Xia, Y. (2017). Study on Main Material Properties and Manufacturing Technology of Raw Bamboo Furniture, Mater's Thesis, Zhejiang A\&F University, Hangzhou, China.

Zhang, C. (2014). The Comprehensive Analysis of Shoot-Culm an Study of Auxin-Related Genes of Phyllostachys Edulis, PhD Dissertation, Chinese Academy of Forestry, Beijing, China.

Zhu, M. J. (2013). "Analysis of the rationality of the existence of Chinese folk bamboo furniture-Taking Sichuan Ya'an small bamboo square stool as an example," Urbanism and Architecture 16, 286-287.

Article submitted: June 15, 2020; Peer review completed: September 5, 2020; Revised version received and accepted: September 24, 2020; Published: October 15, 2020.

DOI: 10.15376/biores.15.4.8981-8994 